\title{
Metodologia de Pesquisa-Ação aplicada a ações interventivas do Centro de Referência de Assistência Social - CRAS I, Salgueiro - PE
}

\author{
Ana Ester Sampaio Angelim ${ }^{1}$; Cláudia Maria Lourenço da Silva ${ }^{2}$
}

\begin{abstract}
Resumo: O Centro de Referência de Assistência Social (CRAS), unidade pública, estatal, capilar do Sistema Único de Assistência Social, visa o estímulo ao trabalho em grupo e o protagonismo social com vistas à superação das vulnerabilidades sociais, conforme preconiza a Política Nacional de Assistência Social (PNAS). A metodologia de pesquisa-ação se aplica a proposta de intervenção dos serviços socioassistenciais da Proteção Social Básica (PSB), pois constitui uma forma de democratização do saber e de engajamento sócio-político, assim o presente trabalho objetiva relatar a experiência do "Projeto Intersetorial Vida Nova", no município de Salgueiro/PE, realizado pelo CRAS I sob perspectiva metodológica de pesquisa-ação, pretendendo responder a seguinte pergunta: como essa Unidade da Proteção Social Básica se constitui como mediador para efetivação das Políticas Públicas em Assistência Social?
\end{abstract}

Palavras-Chave: CRAS; Pesquisa-Ação; Famílias; Relato de Experiência.

\section{Action Research Methodology applied to interventional actions of the Social Assistance Reference Center - SARC I in Salgueiro - PE}

\begin{abstract}
The Social Assistance Reference Center (CRAS), public unit, state , capillary Unified Social Assistance, aims at stimulating group work and social leadership in order to overcome social vulnerabilities , as recommended by the National Assistance Policy social (PNAS). The methodology of action research applies the proposed intervention of social assistance services of Basic Social Protection (PSB) as a form of democratization of knowledge and socio- political engagement, so the present study aims to report the experience of the " Intersectoral Project New life in the city of Salgueiro / PE " conducted by CRAS in methodological perspective of action research, intending to answer the following question : how this Unit Basic Social Protection is constituted as a mediator for the execution of public policies on social assistance ?
\end{abstract}

Keywords: CRAS. Action Research. Families. Experience Report.

\section{Introdução}

A Política de Assistência Social é campo de forças entre visões, interesses, perspectivas, tradições. Dentro de seu processo intenso de transformação se afirma no status das políticas sociais.

\footnotetext{
${ }^{1}$ Discente do curso de Pós-graduação (Lato Sensu) em Gestão Pública Municipal da Universidade Federal do Vale do São Francisco UNIVASF. E-mail: stterana@ gmail.com.br;

${ }^{2}$ Doutoranda em Educação e Ciências pela Universidade Federal do Rio Grande do Sul - UFRGS e Universidade Federal de Santa Maria UFSM; Mestre em Gestão do Desenvolvimento Local Sustentável pela Faculdade de Ciências da Administração de Pernambuco Universidade de Pernambuco - FCAP-UPE, e graduada Ciências Econômicas (com ênfase em Economia Rural) pela Universidade Federal Rural de Pernambuco - UFRPE.
} 
Tendo como avanço o rompimento do vínculo empregatício contributivo na estruturação e concessão de benefícios previdenciários aos trabalhadores rurais e perpassa a visão assistencialista para um embrião de uma política de assistência social amplamente inclusiva (IPEA, 2007).

Cinco anos de debates e lutas pós-Constituição Federal de 1988 para se regulamentar e institucionalizar os avanços conquistados por meio da aprovação, em 7 de dezembro de 1993, da Lei Orgânica da Assistência Social - LOAS trazendo um caráter de maturidade legal aos serviços socioassistenciais.

Como forma de instrumentalizar e operacionalizar a lei e a política é iniciada a construção e a implementação do Sistema Único de Assistência Social (SUAS), que os organiza por níveis de complexidade: Proteção Social Básica (PSB) e Proteção Social Especial de Média e Alta Complexidade.

O Centro de Referência de Assistência Social (CRAS) executa os serviços da PSB que visam o estímulo ao trabalho em grupo e o protagonismo social com vistas à superação das vulnerabilidades sociais. A metodologia de pesquisa-ação e suas fases, por mais flexível que seja dentro de seu planejamento, se aplica a proposta de intervenção dos serviços socioassistenciais da PSB, pois constitui uma forma de democratização do saber e de engajamento sócio-político. A partir de uma tomada de consciência o ser poderá criar mecanismos que leve a um movimento de transição do estado assistencialista passando a ocupar uma posição de sujeito protagonista cidadão.

Assim, o presente trabalho objetiva relatar a experiência do "Projeto Intersetorial Vida Nova", no município de Salgueiro/PE, realizado pelo CRAS sob perspectiva metodológica de pesquisa-ação, pergunta-se como essa Unidade da Proteção Social Básica se constitui como mediador para efetivação das Políticas Públicas em Assistência Social?

\section{Política Nacional de Assistência Social (PNAS): redesenho da política e implantação do Sistema Único de Assistência Social (SUAS)}

O caminho histórico percorrido na construção da política de Assistência Social vem encontrando barreiras em sua consolidação, pois em seu processo de afirmação enquanto 
política de Estado esbarra em sua tradição histórica de caráter clientelista, assistencialista, beneméritas e ações pontuais baseadas em relações de favor.

Para afiançar o previsto na LOAS, desde 1993, movimentos permanente de ações políticas, na tentativa de consolidar a Política de Assistência Social, contam com a participação dos profissionais da área, usuários, entidades de assistência social, conselhos de direitos entre outros, obtiveram como resultado de sua luta a Política Nacional de Assistência Social de 2004 e a Norma Operacional Básica NOB-SUAS.

A Política Nacional de Assistência Social (PNAS) desenvolve e detalha a política de assistência social, traçando o seu direcionamento em termos de gestão, serviços, controle, financiamento. Em acordo com o disposto na LOAS, rege-se pelos seguintes princípios democráticos:

I - Supremacia do atendimento às necessidades sociais sobre as exigências de rentabilidade econômica;

II - Universalização dos direitos sociais, a fim de tornar o destinatário da ação assistencial alcançável pelas demais políticas públicas;

III - Respeito à dignidade do cidadão, à sua autonomia e ao seu direito a benefícios e serviços de qualidade, bem como à convivência familiar e comunitária, vedando-se qualquer comprovação vexatória de necessidade;

IV - Igualdade de direitos no acesso ao atendimento, sem discriminação de qualquer natureza, garantindo-se equivalência às populações urbanas e rurais;

V - Divulgação ampla dos benefícios, serviços, programas e projetos assistenciais, bem como dos recursos oferecidos pelo Poder Público e dos critérios para sua concessão.(BRASIL, 2009a)

A Assistência Social como política de Estado propõe o trabalho integrado às políticas setoriais levando em consideração as desigualdades socioterritoriais com vistas ao seu enfrentamento, à garantia dos mínimos sociais, no provimento de condições para atender contingências sociais e à universalização dos direitos sociais. Sob essa ótica a PNAS objetiva:

- Prover serviços, programas, projetos e benefícios de proteção social básica e, ou, especial para famílias, indivíduos e grupos que deles necessitarem.- Contribuir com a inclusão e a eqüidade dos usuários e grupos específicos, ampliando o acesso aos bens e serviços socioassistenciais básicos e especiais, em áreas urbana e rural.

- Assegurar que as ações no âmbito da assistência social tenham centralidade na família, e que garantam a convivência familiar e comunitária.

(BRASIL, 2009a)

Como requisito essencial da LOAS para dar efetividade à assistência social como política pública foi a construção e implementação do Sistema Único da Assistência Social SUAS. 
Id on Line Revista Multidisciplinar e de Psicoloqia

Id on Line Multidisciplinary Journal and Psycology

Compete ao Ministério do Desenvolvimento Social e Combate à Fome - atualmente, interinamente, Ministério do Desenvolvimento Social e Agrário- e demais gestores da política de assistência social, à frente das secretarias estaduais e municipais, promover a discussão e o processo de reestruturação orgânica da política pública de assistência social na direção do SUAS, desenvolvendo e ressignificando o atual sistema descentralizado e participativo, direcionando os esforços políticos e administrativos necessários ao enfrentamento das grandes e crescentes demandas sociais (BRASIL, 2009a).

O SUAS é um sistema público não-contributivo, descentralizado e participativo que cria instrumentos de operacionalização da lei e da política de Assistência Social no campo da proteção social brasileira. Regula e organiza as ações socioassistenciais de forma articulada entre os entes federados respeitando a diversidade dos territórios.

Como estratégia de gestão o SUAS organiza as ações socioassistenciais por níveis de complexidade (Proteção Social Básica e Especial) com foco prioritário de atenção às famílias e na organização do território, por meio de uma gestão compartilhada entre as três esferas de governo e a intersetorialidade com outras políticas públicas. Na sua implantação e implementação propõe uma gestão participativa com o a participação e mobilização da sociedade civil. Estabelece o financiamento das três esferas de governo em acordo com suas competências e nível de gestão a que está habilitado; propõe uma Política de Recursos Humanos e ainda estabelece o monitoramento e avaliação da política de assistência social.

Embora seja uma realidade a implantação do SUAS nas diferentes instâncias governamentais, sua consolidação vem esbarrando na realidade político-econômica e sociocultural brasileira.

O SUAS regula e organiza as ações socioassistenciais por níveis de complexidade, Proteção Social Básica e Especial que se ocupam dos indivíduos e/ou famílias em situações de vulnerabilidade e riscos (pessoal e social). A primeira com vista na prevenção e a segunda na atuação onde a violação já está instalada, seja ela com ou sem rompimento dos vínculos familiares.

O presente artigo limita-se a discorrer de forma geral acerca da Proteção Social Básica (PSB), nível de complexidade do SUAS ao qual os serviços do Centro de Referência de Assistência Social (CRAS) integram. 
Fazem parte dos Serviços da PSB aqueles que "potencializam a família como unidade de referência, fortalecendo seus vínculos internos e externos de solidariedade, através do protagonismo de seus membros e da oferta de um conjunto de serviços locais que visam a convivência, a socialização e o acolhimento" (BRASIL, 2009a, p.36), em famílias com vínculos familiar e comunitário não rompidos, tais como: Serviço de Proteção e Atendimento Integral à Família (PAIF); Serviço de Convivência e Fortalecimento de Vínculos; e Serviço de Proteção Social Básica no domicílio para pessoas com deficiência e idosas.

Esse nível de proteção vem como forma de responder às necessidades humanas de forma integral, superando atenção a situações emergenciais, ou seja, atuando de forma preventiva, protetiva e proativa com vista ao empoderamento, autocompreensão e a autoestima.

\section{Centro de Referência de Assistência Social (CRAS): unidade de execução direta dos serviços de proteção social básica}

O CRAS é uma unidade pública estatal descentralizada do Sistema Único de Assistência Social (SUAS), que busca organizar e ofertar os serviços socioassistenciais da Proteção Social Básica em seu território de abrangência. Com base em estudos diagnósticos devem ser localizados em área de vulnerabilidade e riscos social.

Essas capilaridades da Política de Assistência Social são responsáveis pela execução de serviços, programas e projetos socioassistenciais da Proteção Social Básica (PSB), potencializando a família, com seus diversos arranjos e particularidades, como unidade de referência.

Tem por público, famílias territorialmente referenciadas, em situação de vulnerabilidade social decorrente da pobreza, do precário ou nulo acesso aos serviços públicos, da fragilização de vínculos de pertencimento e sociabilidade, em especial famílias beneficiárias de programas de transferência de renda e benefícios assistenciais; que atendem os critérios de elegibilidade a tais programas ou benefícios, mas que ainda não foram contempladas; em situação de vulnerabilidade em decorrência de dificuldades vivenciadas por algum de seus membros; e pessoas com deficiência e/ou pessoas idosas que vivenciam situações de vulnerabilidade e risco social. (BRASIL, 2013) 
Serviço de Proteção e Atendimento Integral à Família (PAIF) é o principal serviço da PSB, podendo somente ser executado em uma Unidade de CRAS, tem por finalidade fortalecer a função protetiva das famílias, prevenir a ruptura dos seus vínculos familiares e comunitários, promover seu acesso e usufruto de direitos e contribuir na melhoria de sua qualidade de vida. Está fundamentado na cultura do diálogo, no combate a todas as formas de violência, de preconceito, de discriminação e de estigmatização nas relações familiares, com vistas ao desenvolvimento de potencialidades e aquisições das famílias e o fortalecimento de vínculos familiares e comunitários (BRASIL, 2013).

Os demais serviços complementam as ações do PAIF, podem ser executados por outra unidade/entidade pública ou privada da rede socioassistencial. Todos os serviços da PSB do território devem estar referenciados a uma unidade de CRAS e contribuir com a promoção do acesso do usuário à rede socioassistencial e aos serviços de outras políticas públicas. O planejamento das ações é realizado pelos municípios, de acordo com a territorialização e a identificação da demanda pelo serviço.

As unidades devem contar com equipe técnica composta por coordenação, assistentes sociais, psicólogos, auxiliar administrativo e educadores sociais, entre outros. O quantitativo de cada profissional é definido minimamente pela NOB-RH/SUAS de acordo com o porte do município e quantitativo de famílias referenciadas ${ }^{1}$ na unidade.

A NOB-RH/SUAS (2009b) orienta que o CRAS deve contar com um coordenador, independentemente do porte do município, que tenha em seu perfil profissional nível superior cursado, dentro das formações reconhecidas pelo SUAS, com experiência em trabalhos comunitários e gestão de programas, projetos, serviços e benefícios socioassistenciais.

Os coordenadores são responsáveis pelo planejamento coletivo das atividades, em especial aquelas relacionadas à gestão do território e do CRAS, de pessoal e dos serviços ofertados na unidade da gestão da informação.

Na operacionalização do SUAS, no que diz respeito à gestão do território da PSB se faz necessário:

(...) adequado conhecimento do território, a organização e articulação das unidades da rede socioassistencial a ele referenciadas e a coordenação da acolhida, inserção, encaminhamento e acompanhamento dos usuários, [promoção da articulação da rede intersetorial]. Portanto, a rede socioassistencial deverá ser organizada por meio de

\footnotetext{
${ }^{1}$ Família referenciada: é a unidade de medida de famílias que vivem em territórios vulneráveis e são elegíveis ao atendimento ofertado no CRAS instalado nessas localidades (BRASIL, 2009b)
} 
uma oferta integrada de serviços, programas, projetos e benefícios, a fim de cobrir riscos e vulnerabilidades. (BRASIL, 2016, p. 7)

Os serviços que complementam o trabalho social com famílias devem receber orientações em conformidade com as normativas do SUAS do poder público, estabelecendo compromissos, fluxos e procedimentos reconheçam a centralidade do trabalho com famílias no território.

\section{Metodologia}

O trabalho tem como foco relatar a experiência do "Projeto Intersetorial Vida Nova no município de Salgueiro/PE" realizado pelo CRAS sob perspectiva metodológica de pesquisaação, pergunta-se como essa Unidade da Proteção Social Básica se constitui como mediador para efetivação das Políticas Públicas em Assistência Social?

Para responder a esta questão, aparou-se em abordagens qualitativas de pesquisa científica no qual possibilita aproximar desses fatos e relatá-los. Os dados quantitativos são utilizados apenas para complementar na descrição sobre os sujeitos e espaços onde se dá a pesquisa, sobretudo, no que concerne aos dados sócio-demográficos. Como pode ser visto a seguir.

A pesquisa foi conduzida no Centro de Referência de Assistência Social - CRAS I, localizado em Salgueiro, município do Sertão Central de Pernambuco, nas ações desenvolvidas no período de fevereiro a dezembro de 2012.

No presente trabalho, a pesquisa-ação, se estabelece como meio de conhecer o território, levantar problemas e a partir disso estruturar um plano de intervenção interativoparticipativo para o serviço. Por outro lado, percebe-se este modelo de pesquisa como estratégia de facilitar o envolvimento entre pesquisador/pesquisados.

Torna-se necessário, ainda, o estabelecimento de um referencial teórico para ter sentido, em que a mediação teórica conceitual e metodológica opera na investigação, visto que:

(...) um tipo de pesquisa social com base empírica que é concebida e realizada em estreita associação com uma ação ou com a resolução de um problema coletivo e no qual os pesquisadores e os participantes representativos da situação ou do problema estão envolvidos de modo cooperativo ou participativos. (THIOLLENT, 2009, p.16) 
A metodologia utiliza dois pontos: a participação e a ação. A primeira coloca as famílias como agentes ativos no processo de conhecimento de sua realidade, permitindo às mesmas adquirir conhecimentos necessários para resolução de seus problemas. O último ocasiona o envolvimento dos participantes no processo. A junção dos dois pontos, trazendo o modo de fazer ao estudo, de se apropriar da realidade ao qual estão inseridos já é a ação; ação de organização, de mobilização, sensibilização e de conscientização (BALDISSERA, 2001).

A seguir é descrito as fases da metodologia da pesquisa-ação comtemplando os seguintes pontos: Definição do tema e colocação dos problemas/Elaboração do plano de ação; Reuniões com o grupo; Encontro rede e comunidade/Apresentação do plano de ação; Seminário; Inicio e implementação do plano; Avaliação.

\section{O surgimento da ação}

No início de 2012, a Prefeitura Municipal de Salgueiro traz em seu plano de trabalho o incentivo ao trabalho intersetorial. Foram promovidos encontros de formação sobre a temática com a presença de gestores e técnicos de todas as secretarias presentes no município, como produto propôs-se a construção e execução de projetos.

Junqueira (1999) corrobora que a proposta da gestão intersetorial:

(...) surge como uma nova possibilidade para resolver esses problemas que incidem sobre uma população que ocupa determinado território. Essa é uma perspectiva importante porque aponta uma visão integrada dos problemas sociais e de suas soluções. Com isso busca-se otimizar os recursos escassos procurando soluções integradas, pois a complexidade da realidade social exige um olhar que não se esgota no âmbito de uma única política social (JUNQUEIRA, 1999, p. 27).

O grande grupo foi divido em Grupos de Trabalhos (GT) de acordo com os territórios de atuação. O CRAS I integrou a equipe ao qual faziam parte a Unidade Básica de Saúde e a Escola Municipal Dr. Severino, ambos atuantes no bairro do Planalto.

Durante o processo de discussão para elaboração de proposta de trabalho, a equipe de saúde, aponta como demanda um grupo de famílias que viviam em situação precária - grupo de famílias que o presente artigo trata como "comunidade", conhecida como "Rua da Lama". Inicialmente o GT realizou levantamento das vulnerabilidades do ponto de vista técnico, e propôs ações pontuais de intervenção na comunidade. Posteriormente o CRAS assume o 
trabalho, agregando um caráter continuado e a participativo, utilizando a pesquisa-ação como metodologia em seu processo de educação não-formal, dentro dos conceitos de Michel Thiollent. Com a participação ativa da comunidade o projeto foi intitulado de "Projeto Intersetorial Vida Nova".

\section{Fases da Pesquisa-Ação}

a) Preparação do Pesquisador

A unidade de CRAS já possui o diagnóstico de seu território, fazendo-se necessário a realização de atualização de dados e levantamentos de novas informações junto à Rede atuante no bairro. Impende destaca que a autora exerceu a função de coordenadora da unidade de CRAS em questão.

Com o levantamento de informações foi possível conhecer a realidade da comunidade, na perspectiva de Rede. Na primeira semana de março de 2012 foram realizadas visitas à Comunidade tendo contato com o local e as famílias. Essa ação foi atrelada ao processo de busca-ativa, realizando-se por meio de visitas domiciliares, entrevistas e preenchimento de cadastro padrão da unidade.

Ressalta-se que este instrumental possibilita o levantamento de informações sociais, econômicas, educacionais, de saúde, culturais, dentre outras, ampliando a interpretação da realidade das famílias do local. Gerando os primeiros encaminhamentos para a rede socioasisntencial e demais políticas públicas.

b) Atores Envolvidos

\section{CRAS I: unidade da rede e articuladora de rede}

O CRAS, de nome fantasia CRAS I, é uma unidade de porte médio, que referencia 5.000 mil famílias em situação de vulnerabilidade e risco social em seu território de abrangência, tem capacidade de atendimento de 1.000 famílias/ano. Executa os serviços de 
proteção social básica: Serviço de Proteção e Atendimento Integral à Família (PAIF) e Serviço de Proteção Social Básica no Domicílio para Pessoas com Deficiência e Idosas. Além de elaborar e executar programas, projetos e ações no âmbito social e intersetorial.

No ano de 2012 o CRAS, não contava com uma equipe mínima estabelecida pela NOB-RH/SUAS (2006), possuía uma equipe composta por 01 Coordenação, 01 Assistente Social, 01 psicóloga, 01 pedagoga, 03 técnicos de nível médio. Destaca-se que apenas um técnico possui vínculo por meio de concurso público. Contava com um carro de uso compartilhado com outra unidade de CRAS.

Faziam parte do seu território abrangência os bairros Santa Margarida comtemplando os bairros do Novo Everest e Nossa Senhora de Fátima - , Divino Espírito Santo e Planalto.

A unidade utilizava como premissas no desenvolver de suas ações os princípios da autonomia, diversidade, equidade, interdisciplinaridade, participação e intersetorialidade (BRASIL, 2009).

A qualidade de atendimento é essencial na execução das proteções afiançadas pelo SUAS, e esta qualidade, conforme prevê o PNAS/2004, implica em aspectos relacionados à ética e à clareza dos objetivos profissionais, no desenvolvimento do trabalho realizado com as famílias, sujeitos da Política de Assistência Social (BRASIL, 2009).

As ações desenvolvidas neste serviço, preconizada pela PNAS, proporcionam através de busca ativa, acolhimento individual e em grupo, escuta qualificada, visitas domiciliares, grupos operativos, acompanhamento familiar, articulação e encaminhamento a rede socioassistencial e outras políticas públicas, uma sensibilização a apropriar-se do sentimento de pertencimento enquanto sujeito de direitos e agente transformador de sua realidade.

\section{$\underline{\text { A comunidade }}$}

A comunidade onde se desenvolveu o "Projeto Intersetorial Vida Nova" localiza-se no bairro do Planalto com uma população geral de 4.592 habitantes, segundo o consolidado da unidade de saúde básica do ano de 2012.

A comunidade constituiu-se de forma isolada, em um terreno baldio situado ao centro das Ruas Ulisses Trapiá, Rua Francisco B. Cruz e Rua Joaquim Sá Araújo, tendo nesta última, um beco de acesso às demais ruas. Conforme demonstra a figura 2. 
Figura 2 - Comunidade

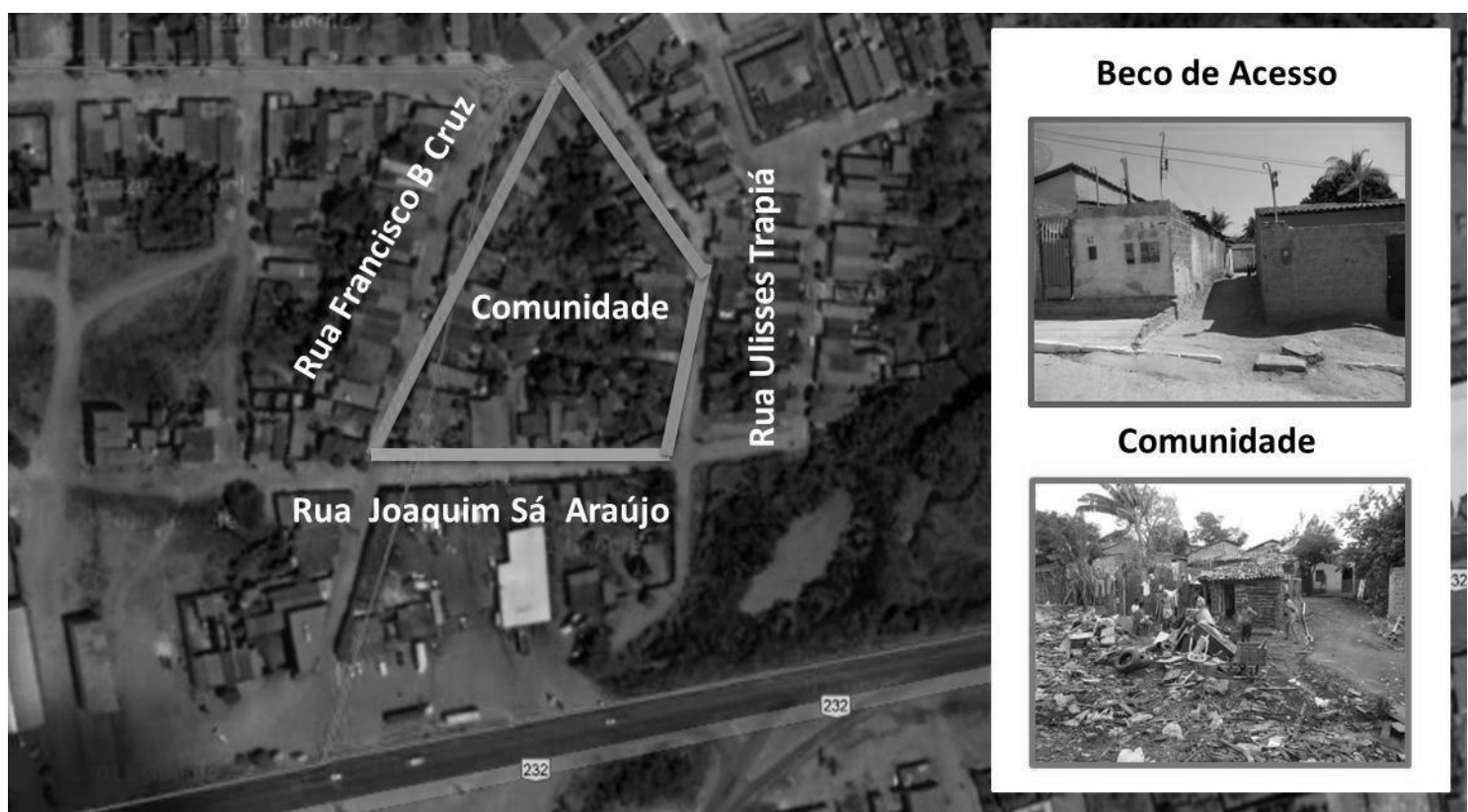

Fonte: Autoria própria.

Era perceptível a falta de condições de habitabilidade, grande presença de acúmulo de lixo, esgoto a céu aberto, sem iluminação pública, sem rede de água e energia elétrica individualizada. Há a presença de habitações de taipa e mista, em situação visível de desabamento. A comunidade era formada por 10 domicílios, habitados por 09 famílias, todas Beneficiarias do Programa Bolsa Família.

A comunidade esta referenciada a unidade de básica de saúde juntamente a Rua Joaquim Sá Araújo, composta por 37 famílias, tento um total de 126 habitantes, dentre eles $49 \%$ são do sexto feminino, $11 \%$ são crianças de 0 a 6 anos, $9 \%$ são pessoas idosas e $0,8 \%$ são pessoas com deficiência. Verifica-se a presença de 5\% de pessoas que fazem uso abusivo do álcool, sendo referente a um valor de 06 (seis) pessoas, onde, dentre estas 05 (cinco) residem na comunidade.

Verificou-se que as famílias referenciavam seus endereços residências à rua denominada de "Rua da Lama", pois para elas, não faziam parte da Rua Joaquim Sá Araújo, (re)afirmando as condições precárias da comunidade. 
Id on Line Revista Multidisciplinar e de Psicologia

Id on Line Multidisciplinary Journal and Psycology

c) Interação Pesquisador e Comunidade e, Desenvolvimento do Plano De Ação

Tendo o conhecimento da comunidade sob a ótica da Rede, passou-se a conhecer a realidade local sob o ponto de vista da Comunidade, ou seja, como essas famílias analisam a realidade à qual estão inseridas.

O Guia de Orientações Técnicas para no CRAS orienta sobre a importância do trabalho em grupo com famílias, sobre como esse espaço de trocas, possibilita o exercício da escuta e da fala, da elaboração de dificuldades e de reconhecimento de potencialidades. Permite aos usuários a oportunidade de melhor viver os seus direitos dentro de um contexto de proteção mútua, afeto, desenvolvimento pessoal e solidariedade (BRASIL, 2005).

O mesmo documento norteador conceitua grupo como “(...) um conjunto restrito de pessoas que, ligadas por constantes de tempo e espaço, e articuladas por sua mútua representação interna, se propõe de forma explícita ou implícita a uma tarefa, que constitui a sua finalidade, interatuando através de complexos mecanismos de assunção e distribuição de papéis.” (PICHON-RIVIÈRE, 1980). (PICHON-RIVIÈRE, 1980, apud BRASIL, 2005, p. 24).

Partindo deste pressuposto, as famílias foram mobilizadas a participar de encontros. Os encontros iniciais objetivaram expor sobre a missão da unidade de CRAS - até então pouco conhecida no território, seja pela Rede ou população -, sobre a proposta de ação intersetorial no município, bem como exposto a metodologia, procedimentos e técnicas da pesquisa; e como essa metodologia possibilitaria a devolução do conhecimento adquirido à comunidade.

Nestes encontros possibilitou-se o resgate histórico da comunidade, desde a origem das famílias, perpassando pela formação da comunidade e parando, inicialmente, na situação em que se encontravam atualmente - neste momento foram expostos fotos tiradas na fase exploratória da pesquisa.

Construiu-se uma linha do tempo com esse resgate histórico, com uma seta apontada para o futuro, tendo em sua ponta uma interrogação. Neste momento foram feitas perguntas provocativas as participantes, com o intuito de fazê-las se perceberem como agentes modificadores de suas realidades. 
Impende destacar, que inicialmente, não houve adesão de todos os membros das famílias às reuniões, fato justificado pela descrença nas ações governamentais. Registra-se a descrença na maioria dos participantes assíduos das reuniões até essa fase da pesquisa. Abrese um parêntese para a não adesão dos homens da comunidade às reuniões iniciais.

Zimerman e Osório (1997) discorrem sobre esse processo de resistência:

Na pré-tarefa (grifo da autora) se concentra a resistência à mudança; é aqui que observamos nos grupos o predomínio das ansiedades e medos basicamente frente ao desconhecido que obstaculizam o "entrar na tarefa". Encontramos também o predomínio da dissociação entre o agir, o sentir e o pensar. [...]O momento da tarefa (grifo da autora) consiste na elaboração da ansiedade provocada pela mudança e na integração do pensar, sentir e agir. É na tarefa que se consegue abordar o objeto de conhecimento de forma a romper com as pautas estereotipadas que estancam a mudança e bloqueiam a comunicação. Aqui se dá o insight através da elaboração dos medos básicos. [...] O projeto (grifo da autora) é o que aparece emergindo da tarefa. (ZIMERMAN; OSÓRIO, 1997, p. 97-98, apud SIQUEIRA, 2008)

Percebendo este ponto foi necessária a inclusão de uma atividade de motivação e esclarecimento quanto ao funcionamento do poder público, incluindo as instâncias de participação popular no planejamento das ações governamentais a nível municipal.

Conforme propõe Thiollent (2009), na etapa subsequente foi promovido o seminário, como forma de examinar, discutir e tomar decisões acerca do processo de investigação. Teve como principal tarefa definição do tema da pesquisa, elaboração da problemática, constituir e coordenar as atividades em equipe, centralizar as informações vindas de várias fontes, buscar soluções e definir diretrizes de ação, acompanhar e avaliar as ações, socialização e divulgação dos resultados.

Para o seminário foram convidadas e mobilizadas as famílias da comunidade e a Rede. Fizeram-se presentes as mulheres, crianças e adolescentes da comunidade; quanto a Rede, apenas representante da Secretaria de Desenvolvimento Social e Obras. No encontro definiuse como tema da pesquisa-ação a "qualidade de vida", estabelecendo como problemática "A Rua da Lama pode se organizar juntamente com a Rede Intersetorial, para melhoria da qualidade de vida das famílias residentes na mesma?" e elaborado um plano de ação, cujo nome ficou intitulado "Projeto Intersetorial Vida Nova"; neste momento ainda foi possível a criação de grupos para desenvolvimento de cada atividade do plano.

Corrobora Thiollent (2009) que construção do plano não diz respeito apenas a resolver um problema de imediato, e sim proporcionar o desenvolvimento da consciência coletiva a 
nível politico-cultural a respeito dos problemas que enfrentam. Esse processo de tomada de consciência está proposto na PNAS no que diz respeito à promoção da autonomia e participação democrática.

Representantes da UBS, por motivo de ações pré-agendadas, não puderam participar do seminário inicial, e prezando pelo princípio da intersetorialidade foi realizado um novo encontro de caráter complementar para a promoção do diálogo com os gestores da política de saúde, como forma de efetivar o atendimento integral às famílias da comunidade.

INOJOSA (2001) expressa que o trabalho intersetorial não deve se limitar apenas ao diálogo ou trabalho simultâneo entre os agentes envolvidos, e sim à procura por resultados integrados. No encontro, a comunidade acolheu a equipe de saúde e apresentou o plano de ação. A equipe fez suas considerações a respeito do plano e se colocou a disposição para participar das atividades.

Dentre as atividades do Plano de Ação pode-se citar:

1. Estabelecer um novo nome para a Rua;

2. Realizar limpeza da Rua;

3. Construção de rede de esgoto;

4. Realização de uma campanha de educação ambiental;

5. Realização de oficinas (maquiagem, trufas e doces finos, salgados, artesanato com garrafa PET);

6. Confraternização natalina.

A atividade proposta de estabelecer um novo nome para a Rua, inicialmente parecia simples e fácil de realizar. Mas, mudanças envolvem o processo de (des)construir uma identidade e (re)construir sob novas perspectivas. Esse processo de empoderamento foi realizado através acompanhamento sistemático em grupo por equipe interdisciplinar do CRAS, com vista aos participantes do projeto se perceberem como sujeitos políticos. Foi intensificado ao longo de 03 meses e depois retroalimentado nas reuniões ulteriores com os envolvidos.

Em paralelo a este período algumas atividades propostas já se concretizavam, o que levou a comunidade a (re)acreditar nas ações governamentais. A Rede foi ampliada com a integração da Secretaria de Serviços Públicos, contando como ponto positivo a participação ativa do secretário da pasta. Esse envolvimento agilizou a realização das ações de aquisição rede de esgoto e limpeza da rua, se tornando ponto positivo e fundamental nessa reconquista. Levando as famílias a observarem que, utilizando os espações corretos de participação 
Id on Line Revista Multidisciplinar e de Psicologia

Id on Line Multidisciplinary Journal and Psycology

popular podem obter êxitos em suas reinvindicações. Dentro de três meses se alcançou estas duas atividades do plano, além de se estabelecer a coleta de lixo dentro da comunidade.

A comunidade havia observado que a maior parte do acúmulo de lixo provinha das residências que circundavam a mesma, por isso a proposta de atividade da campanha de educação ambiental. Nesta atividade os adolescentes e crianças assumiram o papel de protagonistas, sugeriram a elaboração de um folder explicativo da campanha, cuja elaboração, confecção, aprovação e difusão ficaram como atribuições da própria comunidade, apenas sob a orientação técnica do CRAS I.

A temática foi trabalhada em reuniões, houve apresentação do folder elaborado e construída, junto à comunidade, a forma de abordagem nos domicílios vizinhos.

Nesse ponto, que o folder foi elaborado por duas adolescentes, onde uma delas é deficiente intelectual, assistidas pela equipe interdisciplinar do CRAS I, visando estimular a convivência intrafamiliar, social e comunitária cumprindo com a garantia de oferta do trabalho social, como estabelece a Tipificação Nacional dos Serviços Socioassistenciais, direcionado a pessoa com deficiência:

\footnotetext{
à garantia de direitos, o desenvolvimento de mecanismos para inclusão social, a equiparação de oportunidades e a participação e o desenvolvimento da autonomia das pessoas com deficiência (...), a partir de necessidades e potencialidades individuais e sociais, prevenindo situações de risco, exclusão e isolamento. (BRASIL, 2013, p.21)
}

Assim, levando à sensibilização da família com vistas a entender que as limitações da adolescente não a impedem de participar de qualquer tipo de atividade da vida cotidiana. Impende destacar que as demais crianças e adolescentes da comunidade participaram assiduamente e ativamente das ações do projeto.

Foi articulada a presença da "Banda de Lata" - construída de materiais reaproveitados - e o Maracatu do Programa de Erradicação do Trabalho Infantil (PETI). Contou ainda com a participação de toda a equipe da Unidade Básica de Saúde, representantes da Secretaria de Serviços Públicos e Secretaria de Desenvolvimento Urbano de Obras.

Foi realizada a "batucada" nas ruas vizinhas e a conversa "porta a porta" para sensibilização das famílias. Durante o período de realização da pesquisa não houve mais acúmulo de lixo na Comunidade, esse ponto foi levantado em reunião de avaliação do plano. 
Em reunião de avaliação, no quinto mês de implementação do plano de ação, já era perceptível a apropriação da comunidade e da Rede, do novo nome da comunidade "Rua $1^{\circ}$ de Agosto", data da finalização das mudanças estéticas da rua, devido à limpeza e instalação de rede de esgoto, tornando-se um marco da ressignificação positiva da percepção sócioespacial da rua.

Foi sugerida na mesma reunião, a inclusão de mais uma atividade, mudar a estética do beco de acesso à comunidade. Os adolescentes do ProJovem ${ }^{2}$, que participavam da oficina de grafitagem, foram convidados a realizar um processo de intervenção artística na Rua, agora já denominada e apropriada pela comunidade de "10 de Agosto".

Os adolescentes foram à comunidade para execução da intervenção, mas a atividade teve de ser cancelada, pois, segundo o instrutor, não poderia realizar a grafitagem sem que os muros fossem pintados de branco.

Os impasses foram percebidos pela comunidade, as mulheres não possuíam experiência com a pintura em parede e não foi encontrado brecha para a realização dessa atividade com recursos públicos. A comunidade já havia conseguido a doação das tintas. Em momento fervoroso de discursão, os homens da comunidade, que se reuniam sempre em grupo paralelos às reuniões na comunidade para conversar e/ou fazer uso de álcool, levantam, juntam-se ao processo de discussão e assumem a pintura da rua.

Esse ponto, inicialmente de tensão, possibilitou a percepção de que a metodologia utilizada e o trabalho e Rede estavam no caminho certo. Os homens, que até então repreendiam as intervenções da equipe, e que por algumas vezes agiram de forma agressiva, se colocaram dentro das atividades do Plano.

Após pintura do muro os jovens foram recepcionados, desta vez, sem qualquer tipo de solicitação do equipamento, com alegria e guloseimas preparadas pelos participantes do projeto. Ressalta-se que esta acolhida foi realizada pelos homens da comunidade que passaram a participar das reuniões, de forma ativa, e a não fazer uso do álcool antes/durante as atividades, por iniciativa própria.

Ainda dentro do processo de afirmação de identidade da comunidade, em reunião, foi levantada a necessidade de identificação da rua, para que não somente a comunidade e a Rede soubessem do novo nome, mas, também, a população salgueirense. Como proposta foi inclusa

${ }^{2}$ ProJovem Adolescente: Serviço socioeducativo continuado de Proteção Básica de Assistência Social. Extinto em 2013. 
a atividade de confecção de uma placa com o novo nome da Rua. Duas mulheres assumiram o compromisso de confeccionar a placa. Uma semana após a nova pintura da rua a placa já se encontrava pronta e afixada na entrada da rua.

Inicia-se o ciclo de oficinas nos meses de outubro e novembro conforme previsto no Plano. Esse ponto esbarrou em tramites legais de contratação de oficineiros e aquisição de materiais para as oficinas. Para não perder o ritmo das ações e acarretar no desestímulo da comunidade, depois de tantas conquistas alcançadas, a equipe optou por incluir em oficina já existente ofertada pela unidade.

$\mathrm{Na}$ ocasião a oficina de artesanato com garrafas PET, esta tomada de decisão foi delicada, pois exigia sensibilização das mulheres que já estavam em estágio mais avançado do curso, para acolher os novos participantes e retomar algumas técnicas iniciais do curso. Foi perceptível o receio dos novos participantes em entrar em uma nova turma. Como as oficinas desenvolvidas no CRAS, tinha por hábito a participação de técnicos para trabalhar a autoestima e os vínculos, no decorrer das atividades esses pontos de tensão foram minimizados.

Paralelamente a este curso, foram articulados parceiros - pessoas do território do CRAS que tinham interesse em contribuir com a localidade - para realização dos demais cursos de forma voluntária. Assim, conseguindo realizar todas as oficinas propostas no Plano.

No novo encontro de avaliação do Plano, deu-se continuidade a linha do tempo incluindo registros fotográficos e produtos das atividades do plano, que se encerraria com a confraternização de natalina. No processo de avaliação os integrantes decidiram elaborar novo Plano de Ação para o ano de 2013, pois ainda identificavam pontos a serem modificados na comunidade.

As atividades do plano foram encerradas com a confraternização natalina, contando com a presença de representantes da Rede, neste encontro foram apresentados os resultados do projeto. 
Id on Line Revista Multidisciplinar e de Psicologia

Id on Line Multidisciplinary Journal and Psycology

\section{Conclusão}

Verificou-se que a participação dos gestores no processo de discussão e proposição de soluções junto à comunidade, proporcionou a realização de ações públicas condizentes a realidade.

Podemos concluir que com a utilização de metodologia de pesquisa-ação facilitou-se a obtenção de resultados positivos no processo de gestão do CRAS I, proporcionando à comunidade o desenvolvimento de sua autonomia e da participação, na elaboração de soluções adequadas a realidade ao qual estão inseridas, levando-a a se perceber como ser político modelador de sua realidade.

A utilização da metodologia de pesquisa-ação pode ser realizada por outras unidades de CRAS na construção de seus planos de ação, como forma de obter soluções mais adequadas para a superação das vulnerabilidades das comunidades assistidas.

Espera-se que a comunidade concretize o seu desejo de continuar um novo ciclo de ações no ano subsequente; e que tenha um acompanhamento acadêmico, de forma a registrar a evolução e o fortalecimento dos vínculos comunitários que o presente trabalho semeou. Para estudos futuros sugere-se a revisão do presente, a fim de verificar se alcançou o êxito desejado com o passar dos anos. Como estudos complementares apontam-se uma análise da capacidade de mobilização da comunidade e sua influência nas políticas públicas aplicadas ao território.

\section{Referências}

BALDISSERA, A. Pesquisa-ação: uma metodologia do "conhecer" e do "agir". Sociedade em Debate, Pelotas, v.7, n.2, p.5-25, Ago, 2001.

BRASIL. Ministério do Desenvolvimento Social e Combate à Fome. Caderno de Orientações: Serviço de Proteção e Atendimento Integral à Família e Serviço de Convivência e Fortalecimento de Vínculos. Brasília: MDS, 2016.

BRASIL. Ministério do Desenvolvimento Social e Combate à Fome. Política Nacional de Assistência Social (PNAS). Norma Operacional Básica (NOB/SUAS). Brasília: MDS, Reimpressão 2009(a). 
Id on Line Revista Multidisciplinar e de Psicoloqia

Id on Line Multidisciplinary Journal and Psycology

BRASIL. Ministério do Desenvolvimento Social e Combate à Fome. Norma Operacional Básica de Recursos Humanos Do SUAS NOB-RH/SUAS. Brasília: MDS, Reimpressão 2009(b).

BRASIL. Ministério do Desenvolvimento Social e Combate à Fome. Proteção básica do Sistema Único de Assistência Social: guia de orientações técnicas para o Centro de Referência de Assistência Social. Brasília: MDS, out. 2005. Disponível em: <http://www.pg.pr.gov.br/cmas/wp-content/uploads/2011/07/guia_orientacao_tecnica.pdf $>$. Acesso em: 28 ago 2016.

BRASIL. Ministério do Desenvolvimento Social e Combate à Fome. Tipificação Nacional dos Serviços Socioassistenciais. Brasília: MDS,Reimpressão 2013.

INOJOSA, R. Sinergia em Políticas e Serviços Públicos: Desenvolvimento social com intersetorialidade. In/: CadernosFundap, n. 22, p.102-110, 2011.

IPEA - Instituto de Pesquisa Econômica Aplicada. Políticas Sociais. Acompanhamento e Análise, 1995-2005 - Edição Especial, Brasília, Caderno 13, 2007.

JUNQUEIRA L. A. P. Descentralização, intersetorialidade e rede como estratégias de gestão da cidade. In/: Revista FEA-PUC-SP, São Paulo, v. 1, p. 57-72, nov. 1999.

SIQUEIRA, M. M. N. da T. Famílias: uma experiência de trabalho com grupo. Revista Ciências Humanas - Universidade de Taubaté (Unitau) - Brasil, v. 1, n. 2, 2008. Disponível em : <http://periodicos.unitau.br/ojs-2.2/index.php/humanas/article/view/458/414>. Acesso em: 28 ago 2016.

SPOSATI, A. A menina LOAS: um processo de construção da assistência social. $3^{\circ}$ ed. São Paulo: Cortez, 2007(a).

SPOSATI, A. O. Assistência Social: de ação individual a direito social. Revista Brasileira de Direito Constitucional-RBDC.n. 10, jul./dez. 2007(b).

THIOLLENT, M. Metodologia de pesquisa-ação. 17º ed. São Paulo: Cortez, 2009.

\section{Como citar este artigo (Formato ABNT):}

ANGELIM, A.E.S.; SILVA, C.M.L. Metodologia da Pesquisa-Ação Aplicada a ações interventivas do Centro de Referência de Assistência Social - Cras I, Salgueiro - PE. Id on Line Revista Multidisciplinar e de Psicologia, Set-Out de 2016, vol.10, n.31, Supl 2, p. 81-99. ISSN 1981-1179.

Recebido: 30/08/2016

Aceito: $12 / 09 / 2016$ 